\title{
Relationship Between Behavioural Disorders and Social Cognition among Orphans in Saudi Arabia
}

\author{
Huda Othman Alghamdi ${ }^{1}$ \\ ${ }^{1}$ King Abdulaziz Hospital, Jeddah, Saudi Arabia \\ Correspondence: Huda Othman Alghamdi, King Abdulaziz Hospital, Jeddah, Saudi Arabia. \\ Received: December 13, 2019 \\ Accepted: January 20, 2020 \\ Online Published: May 27, 2020 \\ doi:10.5539/ies.v13n6p85 \\ URL: https://doi.org/10.5539/ies.v13n6p85
}

\begin{abstract}
This study aimed to investigate the relationship between behavioural disorders and social cognition among orphans in Saudi Arabia by adopting a phenomenological qualitative approach. To achieve this aim, 50 subjects were selected to participate in this study through a purposive sampling. The participants were subjected to a semi-structured interview session which lasted from 45 minutes to an hour. After data has been gathered, Interpretative Phenomenological Analysis was used to analyse data into themes which were categorized into three: Symptoms of Behavioural Disorders, Social Cognitions, and Factors. The results of the study showed that emotional and behavioural disorders that orphans face in Saudi Arabia were manifested by symptoms of disorders such as Posttraumatic Stress Disorder, Oppositional Defiant Disorder, and Social Phobia. Factors that tend to have a significant effect on behavioural problems among orphans consisted of traumatic events, events prior to admittance in the orphanage such as physical abuse, and the overall physical environment of the orphanage, which can be at risk of being conducive for bullying and fighting among orphans. Furthermore, there might be a relationship between behavioural disorders and social cognition among orphans in Saudi Arabia.
\end{abstract}

Keywords: behavioural disorder, social cognition, orphan

\section{Introduction}

Orphan hood is the state of a child who is left alone to live with no parents or one of them. It is caused by different circumstances that often lead the child to experience various kinds of complications. The absence of parents often results in the abnormal development of the child because there is no one to supervise him/her in the course of his/her growth. The issue of orphanage is one of critical phenomenon that encountered by many societies all over the world. Of these negative impacts that need to be investigated is the social behaviour of orphans resulted from the loss of one or two parents. The behaviour of orphans is one of the disastrous features which make their rehabilitation an up-hill task. The manner in which the orphans are treated by the society and the harsh environments is a critical factor of concern. This study is based on that premise and intends to investigate if there is a significant relation between the social cognition of orphans and behaviour disorders in Saudi Arabia. Many studies have been conducted on this issue; however the question as to whether social cognition as a factor which leads to behavioural disorder is still scarce. This study would help in the intensive research of the cause of orphan's behaviour disorders so as to recommend any interventions for their welfare.

Orphans tend to exhibit deficits in cognitive and social functioning in many studies. They are severely delayed in physical and emotional development (Kaler \& Freeman, 1994). This study is based on the social cognition of orphans in Saudi and its effect on behaviour disorders. Social cognition is one of the features which are very important in the growth of an individual in the society. The various groups of individuals in the society demand a greater attention than others depending on their age and environment with which they are brought up. Orphans are one of the special groups of individuals in the society who are faced by a myriad of challenges and often fail to get social cognition from the environment. Behavioural disorders are one of the characteristics of orphans which are so common. This research aimed at investigating whether social cognition has a relationship with behavioural disorders among the orphans. In order to effectively address the research study, the following research questions have been formulated:

1) What are possible emotional and behavioural disorders that orphans face in Saudi Arabia?

2) What are the possible factors that might influence these behavioural problems? 
3) What elements of social cognition do exist among orphans in Saudi Arabia?

4) Is there a relationship between behavioural disorders and social cognition among orphans in Saudi Arabia?

\section{Theoretical Framework}

Shweder (1991, p. 27) defines cultural psychology as "the study of the way cultural traditions and social practices regulate, express, and transform the human psyche, resulting less in psychic unity for humankind than in ethnic divergences in mind, self, and emotion." Culture entails a set of social beliefs and norms exhibited by a certain group. The human psyche can be defined in its reference to the cultural experience of a person and in return the culture of that person can be identified from his/her behaviour. In the case of the orphans, their behaviours are totally affected by the environment from which they are situated. Therefore, there can be a great difference between the behaviour of orphaned children and non-orphaned children because basically there is a disparity between the environment from which the live.

The family is the basic unit of society and it is where children first experience social interactions and personality development. It is in the family where a child builds the foundations for his or her sense of "self", but how about the children who lost their families? How are they able to live in society? And how are they different from children living in a complete family?

According to the Attachment Theory formulated by Bowlby (1999), there needs to be at least one primary caregiver for a child in order for his or her emotional and social development to become normal. The role of the parents in the development of their child is crucial because it affects different aspects of their humanity. Children make their parents models of their social behaviours; they only adapt and mimic what they can see from their adult caregiver.

Unlike children with families, orphans face the consequences of being deprived of a family because they have no parents that can provide them with affection and support. Felson and Zeilinski (1989) stated that the relation of the parents affects the self-esteem of a child. In their study it shows that children who are very close with and are always supported by their parents have high self-esteem in comparison to their orphaned counterpart. And since this is the case, orphaned children show an unstable self-esteem for the basic reason that they have no one to support them and nurture their potentials.

Harlow (1962) studied the correlation of a mother's affection with the mental development of a child. He conducted his experiments on orphanages and found out that those infants who survived were under the care of their mothers while the rest - even with the basic necessities provided for them by the institution such as food, water and sanitation only — ended in death. This was also carried out with his experiments with animals wherein an infant monkey was separated to its mother and was only provided with a maternal substitute of a cloth figure and a wire figure which provided it with food and water. The monkey only attached itself to its cloth mother to find comfort. Because of the absence of a real mother who can provide it with the care it really needs, the monkey was found out having autistic tendencies. The effect of the absence of an absolute affection shows that children in orphanages also have slow psychological development compared to children who have parents.

Similarly, Zhang (2011) investigated how posttraumatic stress disorder affected orphaned survivors of the disastrous Sichuan earthquake that hit Sichuan province in 2008. The victims of this natural disaster were the children who lost their parents and became orphans due to this tragedy. These orphans showed symptoms of behaviour disorders such as post-traumatic stress disorder because of their exposure to a traumatic experience or natural disaster and loss of their parents that natural disasters such as earthquakes cause orphans more serious mental health problems and these orphans have a higher probability of developing posttraumatic stress disorder (PTSD).

A large number of researchers reported that there was a strong relationship between personality and PTSD development, suggesting that some personality traits such as Neuroticism acted as a lens magnifying the impact of the trauma (Holeva, Tarrier, \& Wells, 2001). In a recent meta-analysed study, Cyniak-Cieciura and Zawadzki (2019) did a meta-analysis and meta-regression studies on 19 articles that dealt with correlation between temperament traits and PTSD systems. After filtering the research studies search, 19 studies met their criteria of inclusion which investigated 6971 people whose ages varied between 18 and 25 and experienced different types of trauma. The results reported moderate and weak relations between components of PTSD symptoms and temperament traits regardless people demographic data.

\subsection{Social Cognition}

Social cognition is a proposition that behaviour is guided by a set of principals called schemas, which are conceptualized in our minds. Schemas are mental structures which contain the knowledge of the world as well as 
its expectations of the world. It is made up of both abstract and specific instances of social objects, furthermore, it encompasses the incoming stimuli as well as the strategies for gathering and interpretation of information related to schema (Kunda \& Thagard, 1996). These schemas therefore are instrumental in prediction and control of the social atmosphere giving guidance to what we attend to, our perception, remembrance and inference. All the schemas have the same functionality of giving meaning to incoming information and that in the memory as well as providing inference in missing links. Schemas are not only functional, but also very significant to our well-being; however, humans are known to be cognitive misers; utilizing the least effort to process the information.

Schemas therefore can be referred to as a mental short-hand used in simplifying the reality and facilitate processing. The known schemas include; person schemas, role schemas, self-schemas, and event schemas (Kunda \& Thagard, 1996). This study aims at investigating whether there is a relationship between the schemas of social cognition and behavioural disorders of orphans.

\subsection{Types Child Behaviour Disorders}

In order to determine the relationship between social cognition of orphans and their behaviour disorders, it is important to identify the different types of behaviour disorders covered in this study. Orphans in Saudi Arabia are different and child behaviour disorders affect each child in a different way. According to the National Institute of Mental Health (NIMH) (MedLine Plus, 2011), there are a number of warning signs that shows a child could be in need of help for a child behaviour disorder. These signs are: harming or threatening themselves, others, or pets; damaging or destroying property; frequent lying or stealing; not doing well in school; skipping school; early smoking, drinking, or drug use; early sexual activity, frequent tantrums and arguments; and consistent hostility toward authority figures

There are three basic types of behaviours. First is the type of behaviour wherein it is wanted and approved. This kind of behaviour is exhibited by normal children who are on time, courteous, mind their manners, and do their homework (NIMH, 2009). One more type of behaviour includes only tolerated behaviour under certain circumstances. Different factors may affect a child's behaviour like being sick, undergoing stress that would lead them to become moody, self-centeredness, and slacking off. Another kind of behaviour is the one that can no longer be tolerated. This kind of behaviour involves hurting other people, disobeying the rules, and breaking the rule (NIMH, 2009). Certain behaviours that can be concerned as a disorder include a child's aggressive behaviour, frequent cheating and lying, tendency for separation anxiety, absenteeism in class, disobedience, fighting and biting, self-injury or hurting other people and uncontrollable temper tantrums (Essorment, 2011). This study aims to determine if there is a significant relationship between these behaviour disorder and social cognitions of the orphans.

The repressed social, cognitive, psychological developments are some of the long-term effects of being an orphan (Johnson, 2011). Studies show that the younger a child loses parents or the age that a child is orphaned, and the longer amount of time that a child remains without a home or family have more drastic impacts on his or her development. This is in relation to the child's inhibited physical development. A child who grows up without parents has a tendency to become shy and is awkward in social interactions because they have been deprived from physical development (NIMH, 2009). Touch deprivation often leads to increasing stress levels and are associated with weakened immune system, and malnourished even if basic the needs are already satisfied. Previous studies show that orphans who are deprived are prone to abnormalities in their physical development. For example, Beegle, Weerdt, and Dercon (2010) found that orphaned children; height had been decreased $2 \mathrm{~cm}$ compared with those who were non-orphaned children. Likewise, Short and Goldbeg (2015), orphaned children were severely infected with HIV and AIDs.

\subsection{The Psychological and Emotional Effects of Orphanhood}

Because of bereavement, the child often experiences the feeling of loneliness and fear. These emotions affect the emotion and the psyche of the child and because they are still inexperienced in terms of handling this kind of matters, the impact that it brings to them may cause them to develop an abnormal character.

Sengendo and Nambi (1997) found that children who lose their parents suffer from both emotional and psychological distress that often become unresolved because there is no one to console them. Children are very delicate beings because they are still under the period of growth and the process of learning. As a result, they tend to absorb what they learn from their experiences and their experience of bereavement may affect them throughout their lives unless they found guidance from an adult. Sengendo and Nambi (1997) found that the orphan has to deal with the changes upon his transition to orphan hood. Changes that he or she needs to cope with include the change in his manner of living. 
Hailegiorgis et al. (2018) carried out a study comparing psychological wellbeing between orphan and non-orphan children whose ages were between 10-18 years old. The researchers used Ryff Psychological Wellbeing Scale to measure the psychological wellbeing for the 370 children who formed their sample of the study. Results revealed that orphaned children scored significantly lower than their counterpart children.

According to Freeman (1993), "social cognition is the study of how people process social information, especially its encoding, storage, retrieval, and application to social situations." This study mainly focuses on the how the participants react with their society. It is also part of the social cognition of the orphans. Their social cognition determines how well they react with other people. It is also explained by Science Daily (2010) that social cognition has the following characteristics:

\subsection{Structures for Development of Orphans}

According to [family jrank.org], there is a significant effect that institutionalization can bring to children. They claimed that children who spent a long period of time in orphanages exhibited deficiency in various areas of development compared to other group of children.

Ames (1997) conducted a study in a Romanian orphanage and found that there were a high percentage of orphanage children who exhibit more complications in behaviour, lower percentage of IQ, more social difficulties, and show more problem regarding insecure attachment patterns. Ames then made a comparison of groups to know the answer to this question. She compared one early adopted child to the Canadian-born group and it showed that the child suffered as many as three of the mentioned problems while the Canadian-born group suffered none of these problems. Three or four of these serious problems were found in 30 per cent of the orphanage group. But her re-analysation of the data, excluding those respondents with three or four problems, found out that there was a no longer any behavioural problem or insecure attachment patterns but there were still a significant number of orphans who had lower IQs than the Canadian-born children.

Because of this result, Ames scrutinized the possible factor that led to three to four complications in children. Included in her list of cause of these problems were the characteristics of the institution, the characteristics of the child, and the characteristics of the family. In her study it showed that the characteristics of the institutions or of the child did not have anything to do with these problems but the length of time the children stayed in the orphanage contributed to the arousal of these problems.

In the same vein, Ong et al. (2015) investigated the factors associated with depressive symptoms among Cambodian orphan children. Data was collected from 606 orphan and vulnerable children whose ages were 11 and above from five provinces in Cambodia. Findings found that children who were unable to attend school or go to work and had witnessed violence in their families were reported of having depressive symptoms. Girls whose parents were divorced or passed away had higher level of depressive symptoms. Besides, there was a high negative correlation between school attachment and depressive symptoms for both boys and girls.

In the context of Saudi Arabia, it seems that there is no single study— to the best of the author's knowledge- has investigated the correlation between behavioural disorders and social cognition among orphans. Therefore, the current study is an attempt to examine this issue among adolescents' orphans who were categorized as having behavioural disorder.

\section{Methodology}

\subsection{Design}

The present study made use of the qualitative research methodology in order to investigate if there is a possible relationship between social cognition and behavioural disorders among orphans in Saudi Arabia.

\subsection{Research Subjects}

The research subjects were orphans from one orphanage in Jeddah, Saudi Arabia. They composed of 50 orphans (both male and female) with an age range of 14 to 20 years. In the selection of the research subjects, several criteria were followed. Aside from the criteria on the age, the subjects must be suspected to have a behavioural disorder as substantiated by the orphanage. In order to sustain the confidentiality of the identities of the orphans, their names have been changed and only the data they provided were used in this study. Purposive sampling was used in the selection of research subjects.

\subsection{Procedures}

Before the data collection process was started, permit to conduct the study was secured from the administrators of the orphanage. This includes the letter of intent an executive summary of the study conducted. Upon approval, a confidentiality agreement was signed between the administration of the orphanage and the researcher in order to 
ensure that all ethical considerations were ensured.

Selection of the research subjects involved the use of a purposive sampling. 50 orphans from the orphanage were selected. Using a semi-structured interview, the research subjects were interviewed one at a time. Each session lasted for approximately 45 minutes to one hour, until all necessary information has been gathered through the use of a voice recorder. At the end of each session, the research subjects were briefed regarding the nature and aims of the study. After the interviews have been conducted, data has been subjected to analysis.

The researcher made use of the Interpretative Phenomenological Analysis in grouping themes individually among the research subjects. Possible relationships were analysed, and common themes were investigated. The analysis was based on the transcribed responses of the subjects during the interview sessions.

\subsection{Interpretative Phenomenological Analysis}

After data collection has been done, information is analysed and interpreted using Interpretative Phenomenological Analysis (IPA). The aim of the IPA is to enable researchers to explore in detail how individuals are putting meaning in their personal as well as their social worlds. The amount of information that is considered useful for this type of study depends on the meanings that particular experiences hold for them. Since this analytical approach is phenomenological in nature, it involves an accurate examination of the experiences of the research subjects, particularly their personal accounts of various objects, places, or events. The analytic procedure involves a dynamic process through the active role of the researcher, with the goal of getting an insider's perspective of the research subject's personal world (Smith \& Osborn, 2008).

\section{Results and Discussions}

\subsection{Establishment of Themes}

Table 1 shows the themes acquired through IPA according to three main categories, which are the symptoms of behavioural disorders, social cognitions, and factors of the research subjects. The thematic categories were established through the results of the interpretative phenomenological analysis conducted on the data gathered. The themes were established based on the responses given by the research subjects during the interview sessions.

One of the main objectives of the present study was to investigate possible behavioural disorders that may exist among the orphans. These were identified as symptoms of behavioural disorders based on criteria of various psychological conditions included in the Diagnostic and Statistical Manual for Mental Disorders. In the interview sessions, it was found that some of the subjects were being disobedient, angry, in fear, shy, and avoiding. Some were also experiencing symptoms such as insomnia, depression, and anxiety.

Disobedience is one of the major symptoms of ODD. In the interview, the theme was established because of subjects' responses indicating disobedience. Some of the subjects manifested this theme through statements such as:

"Things! I really hate talking about it. When I arrived here, I decided that I'm gonna be a lone wolf and take care of nothing else but me. No one's gonna tell me what to do."

Some answered, "I just wanna do things on my own." Statements such as these were found to common among the research subjects. It is for this reason that disobedience was established as one of the themes in the study.

Anger is also one of the symptoms that are included in the DSM-IV. This was also found to be common among the research subjects. When asked about their previous caregivers, some answered, "I hated them." While others stated that they were terrible people. Some of the subjects answered:

"They're all just a bunch of retards!"

These were indicating strong anger. Among the 50 research subjects, around 30 of them manifested angry responses towards different aspects of their life such as the staff of the orphanage, their previous caregivers, recent foster parents, and even anger towards themselves.

Fear was found to be associated with abuses experienced by the research subjects before they were admitted to the orphanage. The result of these abuses is fear. Many of the research subjects mentioned about fear in their responses. One of them responded with:

"I was afraid they were gonna hurt me."

Similar responses were taken from other orphans especially when they were asked to recall experiences with previous foster parents and even their original parents before they became orphans. Some also showed inhibitions in responding to some of the questions regarding their fears because of the abuses that they have experienced beforehand. Some of the research subjects were also found to be shy. Indicators of this theme can be found in many 
of their responses such as:

"No, it's okay. I'm just not used to talking to people."

Because fear as well as being shy was also found to be a common response among the research subjects, it was included in the main list of themes, aside from being potential symptoms of Social Phobia.

Other symptoms were avoidance, depression, and anxiety. After the interview sessions, it was found that these symptoms can be found all in one research subject, which is common to many of them. These were found to be common among subjects who lost their parents in tragedies, accidents, or even crimes. These research subjects often reported about not being able to sleep at night. These were manifested in responses such as:

"It's just that I can't sleep most of the time and I miss my dad." Many of the subjects also indicated being depressed in their responses. Such were found to be "Its even depressing. I didn't imagine that I would end up being like this."

Along with their depression, the subjects reported that they prefer to keep things to themselves. One example is one subject who answered, "No. Uhm... I like to do things on my own." While some stated, "They make me anxious at night."

All these themes were included in the table of themes because these were found to be common among the research subjects. Aside from being common among research subjects, these themes are also categorized as symptoms for behavioural disorders such as PTSD, Generalized Anxiety Disorder, and Major Depressive Disorder.

Responses given by the research subjects were also categorized in terms of social cognitions. The themes were categorized here in terms of the definition of social cognitions as indicated by the literature. Social cognitions in this study are understood as the elements that make up how an individual perceives himself and other people in the environment. The themes terrible, unfair, confusion, misunderstood, mean, scary, and weak, were also conceptions or perspectives of the research subjects towards other people or towards themselves. The word terrible, for one, was established to be a common theme because of the number of times this description was used by the research subjects regarding how they view other people. Some of them answered:

"People are terrible." While others responded with "... and people are terrible."

Oftentimes, research subjects were able to link the term "terrible" with "unfair". This was established using responses such as:

"Yah... This world is really unfair... and people are terrible."

Many subjects perceived the world as unfair and would often perceive the people as terrible. Links were also found to exist between the said themes and being misunderstood. Statements such as "...They don't understand me" were found to be common to most of the research subjects. The terms "mean" and "scary" were also found to be common among the subjects if they had other descriptions aside from "terrible". These themes were found to be present among bullied subjects and those who experienced abuse.

Two of the most common descriptions or cognitions the subjects manifested were reports of being confused and weak. These two themes were established due to frequent responses of confusion among the research subjects. Some of them reported "I don't know. All I can see is a blur" whenever they were asked regarding how they would perceive themselves. Confusion was also revealed through other responses, which mainly involve how they do not know what to do with their lives.

A common perception of subjects towards themselves was found to be weak. This was found to be evident in many of the responses such as:

"Oh no! Not me. I'm a weakling. I could never win against anyone."

Although some of the subjects stated that they would like to be given an opportunity to defend themselves, they appeared to lack the confidence to do such. Because self-perceptions of being weak and confused were found to be very common among the research subjects, these themes were included in the main table of themes.

Gathered data from the interviews have also revealed a number of factors that may have had an effect towards the behavioural problems manifested in the orphans who were the research subjects of this study. Results show that these factors include bullying, abuse, adjustment issues, and life tragedies or traumatic experiences. These themes were categorized as problems that orphans faced while they were admitted to the orphanage. These themes were based on the responses given during the interview sessions and were found to be common among the research subjects.

Bullying was referred as a significant theme among the research subjects of the study. This was established based 
on their responses from subjects (e.g. "No, not really. The other kids would always bully me around and call me names."). Bullying was found significant not just because of the high number of reports of incidents of bullying but because this is often found to be associated with other themes under the category of symptoms of behavioural disorders and social cognitions. For example, some of the subjects view themselves as weak and symptoms such as depression, avoiding behaviours, and shyness also reported that they were often bullied in the orphanage.

Adjustment is also associated with behaviours exhibited by bullied research subjects. Some of the research subjects said that the new environment is a big adjustment to them (e.g. "It's depressing that I'm not living in my own house with my own family. It's a big adjustment for me."). However, this theme was included as a major theme because the results showed that a significant number of orphans were new in the orphanage. These orphans also tend to report adjustment as one of the most eminent concern they face in the orphanage due to dilemmas in making new friends and becoming comfortable in their new environment.

Opposite to the symptoms among bullied were the ones who experienced abuse whether it was inside out outside of the orphanage. Many of them gave statements such as:

"No. My parents died in a car accident. My father would hurt me real bad, especially when he gets home drunk. My mother couldn't do anything about that because even she was often beaten up."

Abuse was also considered as a significant theme because it was able to unify many other themes regarding symptoms such as disobedience, anger, and fear, as well as social cognitions where they viewed people as terrible and the world as unfair.

\subsection{Results Based on IPA}

After data has been gathering using semi-structured interviews, analysis was conducted through IPA. The results of the analysis showed that the responses of the 50 research subjects were divided into three main categories of themes, namely the symptoms of behavioural disorder, factors, and social cognition.

Table 1. Themes from interview data according to symptoms, social cognition, and problems

\begin{tabular}{ccc}
\hline Symptoms of Behavioural Disorder & Social Cognitions & Problems \\
\hline Disobedience & Terrible & \\
Anger & Unfair & Bullying \\
Fear & Confusion & Physical Abuse \\
Shy & Misunderstood & Adjustment \\
Avoidance & Mean & Traumatic experiences \\
Insomnia & Scary & \\
Depression & Weak & \\
Anxiety & & \\
\hline
\end{tabular}

\subsection{Symptoms of Behavioural Disorders}

After the interview sessions of 50 research subjects, it is found out that the subjects were able to manifest a number of symptoms indicative of behavioural disorders. One of the common themes was disobedience. During the interview sessions, some subjects were able to show disobedience in their responses. One subjects, for example, answered:

"It's great, really. But since I'm in this joint I'm told to follow some rules. I don't like following rules."

Some subjects also stated that they would get into fights if they do not get what they want. When they were asked why they like to disobey rules, most of them answered with:

"...I just wanna do things on my own."

Orphans who participated in the study also manifested themes related to anger. This theme was considered because there were a significant number of research subjects who exhibited this symptom during the interviews. Some orphans showed anger towards their parents while some towards themselves. For orphans who showed symptoms of Oppositional Defiant Disorder, their anger was directed more towards their parents and people of authority (e.g. "They were always angry at me. They kept on telling me to eat properly, wear some real clothes, comb my hair, and stuff like that... I hated them."). At times, these orphans appeared to show their anger by shouting and even throwing things. 
There were also a number of research subjects that were found to have both anger and disobedience symptoms. Subjects who tend to have deep anger towards their parents or caregivers (e.g. "I hate him. He never did anything for this family.") tend to manifest this anger on disobedience as a form of rebellion. Also, findings show that these symptoms have an emerging link with the way they perceive people and the way they perceive themselves.

Results also show that many of the subjects manifest fear, depression, anxiety, insomnia, avoidance and shyness, which can be indicative of social phobia, Major Depressive Disorder, PTSD, and even Generalized Anxiety Disorder. One of the subjects stated that she is afraid of people because she fears that they might hurt and bully her around. She stated that:

\section{"...I'm just not used to talking to people."}

She also stated she is afraid of people to the point that it gives her nightmares at night (e.g. "I'm afraid of people... They make me anxious at night."). Some of the orphans reported that they were having sleeping problems. These orphans were found to have experienced a traumatic event before they were referred to the orphanage, such as losing a parent or both parents. One of the orphans responded:

"It's just that I can't sleep most of the time and I miss my dad."

Because of these episodes of sleeplessness, some of the orphans tend to have depressive tendencies as one of them shared:

"Its even depressing. I didn't imagine that I would end up being like this. I don't like this place. It gives me nightmares at night. All I think about is the fire and I can't stop myself from crying whenever I remember."

These themes of responses are common among newly orphaned individuals. For orphans who have experienced traumatic events prior to their entry to the orphanage, some have exhibited symptoms of PTSD, particularly avoiding behaviours such as losing interest in social activities and refusing to gain some friends. They appeared to like to keeping to themselves as one of them answered:

"No. Uhm... I like to do things on my own."

\subsection{Social Cognitions}

During the interview sessions, the research subjects were asked regarding how they view themselves and other people around them or people in general. Most of the responses appeared to be negative as they perceived other people as terrible, unfair, mean, or scary. According to one of the orphans, the world is unfair "... and people are terrible." One orphan who was always bullied around shared that:

"They're mean. All they do is just bully me around."

Some of the orphans who have manifestations of social phobia perceived others as "scary" and would have nightmares about it. How the orphans perceive others tend to complement how they perceived themselves. For those who appeared to show more aggressive perceptions on others tend to see themselves as strong individuals but usually misunderstood. One of the research subjects answered:

“...When I arrived here, I decided that I'm gonna be a lone wolf and take care of nothing else but me."

Statement such as, "They don't understand me." was also found to be common. For orphans who were appeared to me more fearful towards other people, they tend to see themselves as weak, and confused. One of the orphans responded:

"Oh no! Not me. I'm a weakling. I could never win against anyone."

Findings suggest that there may be a significant relationship between behavioural disorders and social cognitions. It appears that how these orphans are able to perceive other people and themselves tend to be connected to the symptoms of behavioural disorders that they are manifesting.

\subsection{Problems Affecting Behavioural Problems and Social Cognition}

Some subjects who manifested symptoms of ODD were found to be victims of abuse when their parents were still alive. Some were able to experience traumatic events which lead to the loss of the lives of their parents, which lead also manifested behavioural problems. It appears that some behavioural symptoms also match others. In the response of one subject, he said:

"When they got angry, I shouted back at them and threw things at them. I was afraid they were gonna hurt me."

This was the same subject who manifested symptoms of ODD. Subjects who exhibited these themes in terms of behavioural conditions tend to be connected to themes of themes of social cognitions which perceive other individuals as terrible and that life is miserable. Later in the interviews, it was found out that these subjects have 
had experiences of abuse by either their caregivers or their parents before they arrived at the orphanage.

Respondents who were observed to be shy were also found to have common social cognitions. Those who exhibited low self-esteem along with symptoms of social phobia revealed that most of them perceived other people as mean and for some cannot be trusted. One of the interesting findings regarding this link is that the two themes tend to have a significant relationship with a single factor, which is bullying. Among all those who participated in the study, it was found out that orphans' problems were limited to bullying, physical abuse, adjustment, and traumatic experiences. Among those with symptoms of social phobia, low self-esteem, and shyness, they revealed that they were victims of bullying while inside the orphanage.

Traumatic experiences were also one of the found common problems that the research subjects were facing. Some of the respondents lost their parents in accidents. Some of them lost their mothers while giving birth to them, while some orphans were able to witness a crime that led to the loss of their loved ones. Results of the analysis showed that this problem tends to have a significant relationship with symptoms of behavioural disorders, particularly depression, insomnia, and anxiety. They were also found to be related to social cognitions of people as being unfair and confusing. They also found themselves to be misunderstood.

\section{Discussions}

The results of the study suggest that there is a relationship between social cognition and behavioural disorders among orphans of Saudi Arabia. One explanation for this relationship lies in the Attachment Theory which states that the presence of at least one care giver is essential to normal emotional and social development (Bowlby, 1999). Orphans who grew up their whole lives in the orphanage tend to substantiate this theory as they manifest different behavioural problems. The absence of parents or a dysfunctional relationship with them tends to hinder their social development. Thus, it may lead to different behavioural conditions and low self-esteem. These findings support Felson and Zeilinski's (1989) findings. Aside from social cognitions, the results of the study also tend to validate the quantitative findings on the relationship of emotional and mental development among individuals as studied by Harlow (1962).

Studies on orphanage as related to different behavioural disorders were also confirmed by the findings of the present study, such as those conducted by Zhang, et al. (2010), and the reports from the National Institute of Mental Health (2009). These suggests that living as an orphan can lead to behavioural problems because of the environment they are exposed to, which appears to deprive them of their physical, psychological, and mental needs, increasing the risks of disorders, violent behaviour, increased sexual promiscuity, and abnormalities in physical development (Beegle et al., 2010; Bingham, 2010; Corr \& Balk, 2010; Johnson, 2011; Zmora, 1994). Moreover, the findings also support previous studies on the notion that the environment produced by the orphanages also significantly affects social, mental, and emotional development among orphans as these institutions serve as their home after they have lost their parents. The physical condition of these institutions tends to have an effect on how orphans perceive themselves and the people around them (Ames, 1997).

\subsection{Conclusions}

Based on the findings of the data gathered and the discussion of linkages with the existing literature, the following conclusions have been formulated. First, emotional and behavioural disorders that orphans face in Saudi Arabia are manifested by symptoms of disorders such as Posttraumatic Stress Disorder, Oppositional Defiant Disorder, and Social Phobia among others. Second, factors that tend to have a significant effect on behavioural problems among orphans consist of traumatic events, events prior to admittance in the orphanage such as physical abuse, and the overall physical environment of the orphanage, which can be at risk of being conducive for bullying and fighting among orphans. Lastly, there appears to be a relationship between behavioural disorders and social cognition among orphans in Saudi Arabia.

\subsection{Limitations and Recommendations}

In light of the study findings, the author recommends conducting many research studies to replicate the current study findings in order to substantiate the claims present in this study and to have more reliable findings as well. As the sample of the current study was not large, future studies are recommended to involve a larger set of participants as well as wider scope of methods used for data collection and analysis. Furthermore, there appears to have too much variety in terms of the research subjects, which tend to produce many other varieties of findings. Thus, it is recommended that future studies should also consider categorizations of orphans as well as of behavioural conditions in order to obtain a more vivid image of trends and patterns. Using an interview was one limitation of the current study. Future research is recommended to triangulate the data collection tool such as questionnaire, observation, and checklist to reach more reliable results. 


\section{References}

Ames, E. W. (1997). The development of Romanian orphanage children adopted to Canada. Ottawa: National Welfare Grants

Beegle, K., De Weerdt, J., \& Dercon, S. (2010). Orphanhood and human capital destruction: Is there persistence into adulthood?. Demography, 47(1), 163-180. https://doi.org/10.1353/dem.0.0094

Behaviour Disorders Organization. (2008). Child Behaviour Disorders. Retrieved from $\mathrm{http} / / / \mathrm{www}$. behaviourdisorder.org/articles1.html

Bowlby, J. (1999). Attachment (2nd ed., Vol. 1). New York: Basic Books.

Corr, C., \& Balk, E. (2010). Children's Encounters with Death, Bereavement, and Coping. New York: Springer Publishing Company.

Cyniak-Cieciura, M., \& Zawadzki, B. (2019). The relationship between temperament traits and post-traumatic stress disorder symptoms and its moderators: meta-analysis and meta-regression. Trauma, Violence, \& Abuse. https://doi.org/10.1177/1524838019876702

Essorment. (2011). Information on the types of behaviour disorders, their causes and symptoms so far identified and what to look for in children. Retrieved from http://www.essortment.com/behaviour-disorders-children-50482.html

Felson, R. B., \& Zielinski, M. A. (1989). Children's self-esteem and parental support. Journal of Marriage and the Family, 51, 727-735. https://doi.org/10.2307/352171

Freeman, S. K. (1993). Analysis of Environmental Deprivation: Cognitive and Social Development in Romanian Orphans.

Hailegiorgis, M. T., Berheto, T. M., Sibamo, E. L., Asseffa, N. A., Tesfa, G., \& Birhanu, F. (2018). Psychological wellbeing of children at public primary schools in Jimma town: An orphan and non-orphan comparative study. PloS one, 13(4). https://doi.org/10.1371/journal.pone.0195377

Harlow, H. F. (1962). The heterosexual affectional system in monkeys. American Psychologist, 17, 1-9. https://doi.org/10.1037/h0043587

Hobday, V., Law, G. U., \& Howard, R. (2015). A Tale of Two Diagnoses: An Interpretative Phenomenological Analysis of Healthcare Professionals Working with Children with Type 1 Diabetes and Coeliac Disease. International Journal, 3(4), 139-147. https://doi.org/10.12691/ijcd-3-4-10

Holeva, V., Tarrier, N., \& Wells, A. (2001) Prevalence and Predictors of Acute Stress Disorder and PTSD Following Road Traffic Accidents: Thought Control Strategies and Social Support. Behavior Therapy, 32, 65-83. https://doi.org/10.1016/S0005-7894(01)80044-7

Johnson, W. (2011). The Effects of being an Orphan. Demand Media Inc.

Kaler, S. R., \& Freeman, B. J. (1994). Analysis of environmental deprivation: Cognitive and social development in Romanian orphans. Journal of Child Psychology and Psychiatry, 35(4), 769-781. https://doi.org/10.1111/j.1469-7610.1994.tb01220.x

Kunda, Z., \& Thagard, P. (1996). Forming impressions from stereotypes, traits, and behaviors: A $\begin{array}{lllll}\text { parallel-constraint-satisfaction theory. Psychological review, } & \text { 103(2), } 284 .\end{array}$ https://doi.org/10.1037/0033-295X.103.2.284

MedLine Plus. (2011, June 2). Child Behaviour Disorders. Retrieved from Medline Plus Trusted Health Information for You. Retrieved from http://www.nlm.nih.gov/medlineplus/childbehaviourdisorders.html

National Institution of Mental Health (NIMH). (2009). Treatment of Children with Mental Illness. Frequently asked questions about the treatment of mental illness in children.

Ong, K. I. C., Yi, S., Tuot, S., Chhoun, P., Shibanuma, A., Yasuoka, J., \& Jimba, M. (2015). What are the factors associated with depressive symptoms among orphans and vulnerable children in Cambodia? BMC psychiatry, 15(1), 178. https://doi.org/10.1186/s12888-015-0576-9

Sengendo, J., \& Nambi, J. (1997). The psychological effect of orphanhood: A study of orphans in Rakai district. Health Transition Review, 7, 105-124.

Short, S., \& Goldber, R. (2015). Children Living with HIV-Infected Adults: Estimates for 23 Countries in sub-Saharan Africa. PLoS ONE, 10(11), e0142580. https://doi.org/10.1371/journal.pone.0142580 
Shweder, R. (1991). Thinking Through Cultures: Expeditions in Cultural Psychology. Massachusetts: Harvard University Press.

Zhang, M. L. (2010). Personality predictors of posttraumatic stress disorder in orphaned survivors of the Sichuan earthquake. https://doi.org/10.2224/sbp.2010.38.8.1057

Zmora, N. (1994). Orphanages reconsidered: Child care institutions in progressive era Baltimore. Philadelphia: Temple University Press.

\section{Copyrights}

Copyright for this article is retained by the author(s), with first publication rights granted to the journal.

This is an open-access article distributed under the terms and conditions of the Creative Commons Attribution license (http://creativecommons.org/licenses/by/4.0/). 